\title{
Elena Romero, El profeta Moisés, divino y humano: su grandeza y su muerte. Versiones sefardies de dos leyendas hebreas medievales, Madrid, CSIC, 2017, 363 pp.
}

El corazón de este nuevo libro de Elena Romero es la edición de todo el corpus conocido de versiones judeoespañolas, originalmente en caracteres aljamiados, de las leyendas midrásicas conocidas como Guedulat Mosé (La grandeza de Moisés) y Petirat Mosé (La muerte de Moisés). Las dos hunden sus raíces en una internacional tradición que floreció, en el ocaso de la Edad Media y luego durante la Edad Moderna e incluso la Contemporánea, en el colosal repositorio del midrás en hebreo, aunque dejó traducciones, proyecciones y secuelas en otras lenguas, empezando por el yídico.

De La grandeza de Moisés se editan seis textos: los llamados de Constantinopla ca. 1765, Salónica 1855 (con escrupuloso desentrañamiento de todas las variantes de Salónica 1855B y Salónica 1891), Belgrado 1860, manuscrito de Oriente del siglo XIX, y manuscrito de Tetuán de 1891. De La muerte de Moisés se editan las versiones de Constantinopla 1763, Salónica 1900, Burgas 1919, Constantinopla 1879 y manuscrito de Oriente del siglo XIX. Son todas leyendas en prosa. Elena Romero añade la edición de dos coplas sefardíes en verso relacionadas, por su tema, con los textos anteriores: un extracto de Las hazañas de Moisés, conforme al manuscrito de Sarajevo-Venecia 1702 y ss, y dos versiones de La muerte de Moisés: Esmirna 1861 y Rodas 1902/1948.

Solo la experiencia de la lectura directa, y no la de la reseña abreviada, puede permitir tomar conciencia de la opulencia y la expresividad de la lengua sefardí en que todos estos relatos están codificados; del valor de su léxico, de sus fórmulas, de sus giros, como señales de estratos y de cruces intrincadísimos, no solo lingüísticos, sino también culturales en el sentido más amplio; de su fuerte halo emocional, pues no en vano sus traductores, refundidores, transmisores y receptores sefardíes se sintieron víctimas de otro éxodo que había sobrevenido (desde el solar hispano) bajo la sombra y entre los ecos sentimentales y narrativos de los éxodos anteriores que padeció el pueblo judío (y no solo del que estuvo guiado por Moisés); y de su valor trascendental, en fin, como literatura de aliento muy poderoso y como revelación de unos géneros de narración y de unas estrategias de traducción, o quizás debiera decirse de adaptación, que enriquecen de modo superlativo no solo el panorama de la literatura sefardí en particular, sino también el de la literatura hispánica en que la sefardí tiene su marco.

Aunque estaría por ver en qué grado cuadra la etiqueta de «folclórica» a unos textos que fueron trasvasados de manera directa desde las fuentes midrásicas (y por tanto primordialmente orales y tradicionales, pero fijadas subsidiariamente por la escritura) hebreas a los papeles de sus intérpretes sefardíes, la lectura y el análisis de todos y cada uno de estos relatos y variantes constituyen un verdadero festín para el aficionado, en particular, a la literatura folclórica. El encadenamiento de motivos tradicionales es abrumador y se ajusta a unos modos y a unas poéticas de la interpolación y el ensamblaje que para cualquier conocedor de la literatura tradicional resultan bien familiares. Esta apreciación corrobora que estamos ante una tradición literaria más cercana a los gustos más libres e informales del pueblo que al dogma escolástico de los rabinos. En el polo opuesto, en definitiva, a las traducciones y adaptaciones, más literales, incluso rígidas, 
que se hacían en la órbita sinagogal. Un trabajo muy reciente de Olivier Brisville-Fertin, «Quelques réflexions sur le statut et les fonctions des traductions aljamiadas de prédication», Cahiers d'études hispaniques medievales [Monográfico Penser la traduction au Moyen Âge] 41 (2018) pp. 275-293, aunque centrado en el ámbito de la traducción y de la aljamía árabes, nos permite calibrar mejor la diferencia, puesto que el autor francés se fija en las traducciones más fieles a las escrituras canónicas y más renuentes a la contaminación folclórica. Es decir, en el extremo opuesto al que a nosotros nos ocupa.

Particular interés tienen, desde el punto de vista de la interpolación de motivos del cuento y la leyenda tradicionales, las sensacionales versiones de Burgas 1919 y Manuscrito de Oriente, siglo XIX, de La muerte de Moisés. En Burgas 1919 se halla intercalado el episodio de un encendido debate de Moisés primero con Abraham, después con Isaac y finalmente con Jacob que sigue las convenciones del género literario del debate, que cuenta con muchos paralelos en la literatura sefardí, en la hebrea, en la hispánica y en otras (particularmente en la medio-oriental antigua, con la que la hebrea antigua tuvo lazos); en ese mismo texto de Burgas se integra también una digresión legendaria fascinante acerca de cómo, nadando por el río, llegó hasta Moisés el sarcófago que unos hechiceros egipcios habían ocultado y sumergido en las aguas, con los huesos de José en su interior, lo que permitiría cumplir a los prófugos judíos con el precepto de no abandonar Egipto si no era con los restos del patriarca.

Valdría la pena, sin duda, evaluar hasta qué punto este motivo narrativo del sarcófago de José escondido en el río tiene relación con las leyendas medio-orientales e indoeuropeas acerca de otros héroes o soberanos enterrados en los ríos que ha estudiado François Delpech en «Trésors et sépultures subaquatiques: variations sur une légende perdue», en Routes et parcours mythiques: des textes à l'archéologie, ed. Alain Meurant (Bruselas: Safran, 2011) pp. 37- 78; y en «La sépulture subfluviale de Daniel et le mystère indo-européen du feu dans l'eau», Voix des mythes, science des civilisations (Mélanges Philippe Walter), eds. Fleur Vigneron y Koji Watanabé (Berna: Peter Lang, 2012) pp. 3 16.

En el Manuscrito de Oriente, siglo XIX, de La muerte de Moisés, hay, por otro lado, interpolados cuentos y ejemplos de distinta especie (La prometida del rey, ¿es fea o bella?, La novia indecisa, El cortesano que regaló al rey una espada, otra versión menos desarrollada del debate de Moisés con Abraham, Isaac y Jacob, Los seis pecados de Moisés, La madre que defendía a su hijo), y no pocos episodios que no asoman en otras fuentes, como el del traspaso de la sabiduría de Moisés a Josué, que tiene un interés crucial si se aprecia desde la atalaya de la literatura acerca de la transmisión de la soberanía y del saber de un dirigente más experto a uno más joven, que es motivo central en muchas mitologías iniciáticas y en una muy reincidente y prestigiosa bibliografía crítica.

Pero no es solo el encadenamiento más o menos aleatorio de motivos narrativofolclóricos flotantes, migratorios, lo que sitúa con claridad estos relatos en la órbita de la literatura de raíz tradicional. La estructura general de La grandeza de Moisés se atiene al dilatadísimo género de las visiones del más allá, sobre las que muchos siglos, lenguas y literaturas han insistido una y otra vez. Un repertorio tan abierto y multifacético como para que, por ejemplo, el especialista en Dante no se equivoque si juzga que la dramática excursión de este Moisés midrásico-sefardí por los cielos, los infiernos y el paraíso puede ser un parangón legítimo de la sofisticadísima Commedia; sí, tendrá razón, pero siempre y cuando no pierda de vista que tales ambulantes Moisés y Dante (igual que tantos otros 
protagonistas de visiones alegóricas del más allá, muchas de ellas vertidas en el molde del cuento oral, otras en el del relato chamánico, no pocas en escritos de grandes refinamiento y cortesanía) no dejan de ser, a fin de cuentas, planetas de una dilatadísima constelación literaria que cuyos cimientos se asientan sobre un folclore difuso e inmemorial.

En lo que respecta al sustrato folclórico que es posible apreciar en los relatos acerca de La muerte de Moisés, cuya idea principal es la resistencia de Moisés a entregar el alma a sucesivos enviados de Yahvé y a Yahvé mismo, puesto que el patriarca desea fervientemente poder ingresar en la ya muy cercana tierra prometida, baste decir que la propia tradición sefardí atesora endechas protagonizadas por humanos que se resisten en vano, y que oponen argumentos apasionados, a la visita de la muerte. Véase al respecto Manuel Alvar, «Las coplas de la muerte y la tradición sefardí», Endechas judeoespañolas (Madrid: CSIC, ed. refundida y aumentada, 1969) pp. 45-58; y Samuel G. Armistead y Joseph H. Silverman, «Las Coplas de la muerte y una endecha de Esmirna», En torno al romancero sefardí: hispanismo y balcanismo de la tradición judeoespañola (Madrid: Gredos-Seminario Menéndez Pidal, 1982) pp. 89-95.

El de la rebeldía al mandato a morir es, sin duda, materia de un sinnúmero de cuentos y de leyendas tradicionales e internacionales. Y, por supuesto, de películas tan clásicas como El séptimo sello, 1957, de Ingmar Bergman. Pero hay motivos específicos dentro de la trama de alguna versión de La muerte de Moisés sefardí que llaman particularmente a la comparación. Así, los episodios de la hermosísima versión de Constantinopla 1763 a los que Elena Romero ha marcado con los epígrafes «Empieza la cuenta atrás: a Moisés le quedan cinco horas de vida; pide a Josué que proteja a su familia...», «Le quedan tres horas; Moisés suplica a Dios que le deje entrar en la tierra prometida...», «Le quedan dos horas...», «Le queda media hora...», «Llega la hora de la muerte...», se pliegan a unas cronologías formulaicas que no dejan de recordar episodios y versos de romances como aquellos de La muerte del príncipe don Juan que decían: «tres horas tienes de vida, hora y media ya pasada, / la una para desponer de las cosas de tu alma, / media para despedirte de las gentes de tu casa...». Escenas de factura análoga aparecen en romances de documentación renacentista como El enamorado y la muerte ( «- $\mathrm{Oh}$, muerte tan rigurosa, déjame vivir un día! / —Un día no puedo darte, una hora tienes de vida...») o vivos hasta hoy en la tradición oral moderna, como el de El ateo: «Cuando fuera esoutro día, la Muerte por él venía, / cuatro demonios de negro, de blanco nada traían. / -Detente, Muerte, detente, detente siquiera un día, / pra confesar mis pecados, confesar la alma mía. / - Cómo me he deter, señor, si el rey del cielo nos guía...».

Todo esto si nos ceñimos solo, y de manera muy sucinta, al campo del romancero. Porque lo cierto es que el esquema narrativo de La muerte de Moisés, que explota el pathos del acercamiento hora a hora del final de quien está destinado a morir, se ciñe de manera escrupulosa a un esquema literario muy acuñado y de proyecciones vastísimas, al que también se hallarían ligados, por poner unos pocos y variados ejemplos entre muchos posibles, la crónica de la espera de la muerte del filósofo en la Apología de Sócrates, el relato evangélico de la pasión de Cristo, la epopeya carolingia de la aniquilación de Roldán, la tragedia lorquiana de Mariana Pineda o la película Bailar en la oscuridad (2000) de Lars von Trier.

El trabajo de edición de Elena Romero está a la altura del tesoro invaluable que exhuma en este libro. En su prólogo explicita, en primer lugar, «cómo se fue forjando este libro» y reflexiona «sobre el título», al tiempo que define su contenido, su sistema de 
transcripción y sus criterios generales de edición, que siguen los que fijó para la edición de textos sefardíes Iacob M. Hassán, el fundador de la escuela española de estudios sefardíes. Abruma el modo en que Romero transcribe y edita estos textos dificilísimos, acribillándolos con exhaustivas notas léxicas, lingüísticas y culturales, declarando con rigor todas sus fuentes bíblicas y parabíblicas, aclarando los pasajes (que son muchísimos) de difícil comprensión, y llenando lagunas a partir de lo que sugieren las fuentes bíblicas y midrásicas o los paralelos sefardíes.

Describe y filia con rigor cada versión (algunas muy diferentes entre sí), busca y compara con sus fuentes hebreas (por más que haya casos que resultan casi imposibles de desentrañar, como el de la fantasiosa versión de Constantinopla 1763 de La muerte de Moisés), introduce deslindes en las complejísimas cuestiones de angelología, mística y escatología hebreas, indispensables para cualquier comprensión de estos relatos, analiza con detenimiento la lengua sefardí de una versión del Estrecho, da cuenta minuciosa del «desarrollo de abreviaciones hebreas y judeoespañolas», construye un completo glosario de más de treinta páginas, y establece una completa bibliografía de fuentes sefardíes y de fuentes hebreas y arameas, además de un índice de versículos bíblicos en judeoespañol y otro índice onomástico de autores y editores sefardíes.

Tras hacer el elogio del libro que tenemos entre manos puedo ya extenderme acerca de la tradición narrativa y crítica general a la que viene a sumarse y, sobre todo, a enriquecer.

Porque, si el Moisés del relato bíblico era una especie de constructo heroico en el que se adosaban motivos narrativo-folclóricos que venían de la noche de los tiempos, y de quién sabe qué ignotas y enredadas tradiciones orales, sobre el Moisés que aquel Libro fijó por escrito no han dejado de seguir acumulándose milenios de glosas y de invenciones añadidas, casi siempre de extracción (en instancias cercana o lejana) oral o folclórica, que han ido modelando, hasta hoy, un personaje absolutamente disforme, polifacético, cuyos contornos, por inabarcables, no lograremos jamás escrutar en todos sus alcances.

Moisés ha sido el centro de un proceso o más bien de una suma de procesos de ficcionalización que no resultan tan raros en un acervo, el bíblico, que ha alimentado las memorias y estimulado la creatividad literaria de un sinfín de pueblos y de generaciones. Lo prueban, en mayor o menor medida, las celebérrimas parejas de Adán-Eva, Caín-Abel o Judith-Holofernes, y las epopeyas personales de, entre otros, Noé, Abraham, José, David, Salomón o Sansón, sobre los que tan sin medida se han acumulado divagaciones e invenciones. En España tuvimos, por cierto, a un folclorista eximio, Julio Camarena, que se embarcó en la tarea de intentar desentrañar las relaciones entre relatos bíblicos y literatura oral española. La muerte injusta y prematura le impidió desarrollar hasta donde hubiera podido aquella magna empresa, aunque tuvo tiempo de regalarnos dos trabajos fundamentales: «La tradición oral en el Antiguo Testamento. Aproximación al legado de los patriarcas», Estudos de literatura oral 9-10 (2003-2004) pp. 57-78; y «La tradición oral en el Antiguo Testamento. La herencia de los patriarcas-profetas», Estudos de literatura oral 11-12 (2005-2006) pp. 33-50.

La mayoría de los héroes bíblicos, con Moisés a la cabeza, se ajustan a esquemas no demasiado convencionales en los usos de la literatura místico-heroica, pues suelen quedar resaltados sus perfiles positivos, pero sin que queden en la sombra sus defectos humanos y sus relaciones muchas veces conflictivas con la divinidad. Ello les confiere una profundidad y una ductilidad psicológicas que no tienen demasiados parangones en otras tradiciones, más dadas a la exaltación de héroes resplandecientes y sin fisuras. 
No solo en la literatura doctrinal y para-doctrinal (e incluso en la extra-doctrinal y no autorizada) de las grandes religiones monoteístas (el judaísmo, el cristianismo, el islam, el bahaísmo) y de sus respectivas sectas ha sido Moisés un personaje sometido a procesos intensísimos, a veces extravagantes, de reciclaje literario. En las tradiciones orales de no pocos pueblos originarios de Asia, de África o de América han asomado y siguen haciéndolo una buena cantidad de avatares más o menos calcados o inspirados por el Moisés bíblico, pero que han dado el salto a órbitas culturales en que el vínculo con aquel modelo no resulta explícito, por más que pueda detectarse de manera subliminal.

Tal se aprecia, por ejemplo, en el Dulu Bon Be Afri Kara, una epopeya (publicada muchas veces desde 1948) muy estilizada e idealizada de la migración del pueblo fang desde el este hasta las costas del África occidental, refundida por Ondoua Engute a partir esencialmente de materiales orales consuetudinarios, pero muy influida también por los relatos de las misiones cristianas. El Dulu Bon Be Afri Kara se propuso calcar de la fuente bíblica la deriva exílica de todo un pueblo africano, y convertir al patriarcal Afiri Kara en un carismático Moisés negro. Al respecto puede verse la traducción de Julián Bibang Oyee que lleva el título de La migración Fang, Dulu Bon Be Afrikara (Ávila: Malamba, 1995); y además Lluís Mallart Guimerà, Un cant èpic africà. Una crítica al poder absolut (Tarragona: Publicacions de la Universitat Rovira i Virgili, 2014) pp. 111-112.

Tan bien dispuesto ha estado el personaje de Moisés a impregnar y a ser impregnado por relatos fabulosos de toda índole, que hasta en torno al ayatolá iraní Ruhollah Musaví Jomeini hubo y hay una intensa producción de discursos que han hecho de él, para muchos de sus seguidores, una especie de Moisés de la rama chií del Islam, adornado de relatos legendarios de enorme interés. Al respecto puede leerse el fascinante libro de Li Kulli Fir'awn Musa, The Myth of Moses and Pharaoh in the Iranian Revolution in Comparative Perspective (Waltham MA: Brandeis University, 2010).

La bibliografía crítica acerca de las metamorfosis literarias de Moisés es verdaderamente torrencial. Me limitaré a dejar constancia aquí, como referencias de importancia mayor, de solo tres títulos: Yuval Harari, «Moses, the Sword, and The Sword of Moses: Between Rabbinical and Magical traditions», Jewish Studies Quarterly 12 (2005) pp. 293-329; La construction de la figure de Moïse, ed. T. Römer (París: Gabalda, 2007); y, sobre todo, René Bloch, Moses und der Mythos: Die Auseinandersetzung mit der griechischen Mythologie bei jüdisch-hellenistischen (Leiden-Boston: Brill, 2011). Las páginas de todos ellos, que remiten además a amplias bibliografías enormes, facilitan la percepción de la polifonía abigarrada del personaje y de sus dobles. Se ha llegado hasta a hablar de saturación del esquema narrativo del Éxodo como modelo (en el ámbito de las tradiciones narrativas del judaísmo helenístico, por ejemplo) de largas generaciones de derivados, según puede leerse en Erich S. Gruen, «The Use and Abuse of the Exodus Story», The Construct of Identity in Hellenistic Judaism Book. Essays on Early Jewish Literature and History (Berlín: De Gruyter, 2016) pp. 198-227.

Si me he tomado la libertad de cerrar esta reseña con unos trazos muy generales acerca de las abigarradas tradiciones literarias (y de la correspondiente bibliografía crítica) que han hecho de Moisés un héroe de cuentos y de leyendas que acabaron, en muchos casos, por tener poco o muy poco que ver con la letra del modelo bíblico, es para que pueda ser valorada desde una perspectiva más justa y amplia la enorme aportación que supone el libro El profeta Moisés, divino y humano: su grandeza y su muerte. Versiones sefardies de dos leyendas hebreas medievales, que permitirá, o más bien que obligará a que, a partir de ahora, el corpus sefardí, y gracias a él el hispánico (huelga decir que el primero es parte, y valiosísima, del segundo), puedan entrar por la puerta grande 
de la bibliografía crítica acerca de las fábulas mosaicas, de las que había estado lamentablemente excluido hasta ahora, si hacemos la salvedad de algunos interesantísimos recontamientos moriscos relativos a Moisés que no han atraído hasta hoy demasiado interés crítico.

Toda una gesta filológico-cultural, la que se sustancia en este libro, que logra colocar la literatura sefardí inspirada en la leyenda hebrea, y su estudio y su crítica, en lo más alto de la profusa bibliografía internacional acerca de la literatura midrásica y de sus proyecciones, de la que estaba hasta ahora rigurosamente excluida. Y un alarde, de paso, de compromiso humanista, que restituye a la literatura y a la cultura del mundo hispánico una rama (la de la leyenda tradicional sefardí surgida del Midrash hebreo) prácticamente incógnita, a pesar de su gran mérito.

José Manuel Pedrosa

(Universidad de Alcalá)

$$
9
$$

